\title{
Preparation and Physical Chemistry Characterization of New Nanostructured Oxides Catalysts by Spray Pyrolysis Method for the Biodiesel Production
}

\author{
Silvania Lanfredi ${ }^{1, a}$, Elisabeth Djurado ${ }^{2, b}$, Marcos A.L. Nobre ${ }^{1, c}$ \\ ${ }^{1}$ Faculdade de Ciências e Tecnologia - FCT, Universidade Estadual Paulista - UNESP, \\ Laboratório de Compósitos e Cerâmicas Funcionais - LaCCeF, C. P. 467, \\ CEP: 19060-900, Presidente Prudente, SP \\ ${ }^{2}$ Centre National de la Recherche Scientifique (CNRS) - University Grenoble Alpes, \\ Laboratoire d'Electrochimie et de Physico-chimie des Matériaux et des Interfaces-LEPMI, \\ 1130 rue de la Piscine, BP 75, 38402 St Martin d'Hères, France \\ asilvania@fct.unesp.br, belisabeth.djurado@lepmi.grenoble-inp.fr, 'nobremal@fct.unesp.br
}

Keywords: Double perovskites, Spray pyrolysis method, Titanates, X-ray diffraction

\begin{abstract}
In this work were synthesized new catalysts of stoichiometries $\mathrm{Sr}_{0.8} \mathrm{~K}_{0.2} \mathrm{TiCu}_{0.10} \mathrm{O}_{3}$, $\mathrm{Sr}_{0.7} \mathrm{~K}_{0.3} \mathrm{TiCu}_{0.15} \mathrm{O}_{3}$ and $\mathrm{Sr}_{0.5} \mathrm{~K}_{0.5} \mathrm{TiCu}_{0.25} \mathrm{O}_{3}$ by spray pyrolysis method. The synthesis conditions were optimized to obtain single phase powder of titanates of double perovskite structure, with an ultrasound vibration frequency of $1.3 \mathrm{MHz}$ at $700{ }^{\circ} \mathrm{C}$ under air flow. The average crystallite size of the powders, determined by the Scherrer equation and using the Jade Plus 8 software, was at around $9 \mathrm{~nm}$. The powder morphology was analyzed by scanning electron microscopy (SEM). The $\mathrm{Sr}_{0.5} \mathrm{~K}_{0.5} \mathrm{TiCu}_{0.25} \mathrm{O}_{3}$ system showed particles with smooth surfaces, spherical and with smaller agglomerates than $\mathrm{Sr}_{0.8} \mathrm{~K}_{0.2} \mathrm{TiCu}_{0.10} \mathrm{O}_{3}, \mathrm{Sr}_{0.7} \mathrm{~K}_{0.3} \mathrm{TiCu}_{0.15} \mathrm{O}_{3}$ systems. This phenomenon suggests that the stoichiometry changes the aspect of the particle surface, which may influence in the catalytic activity. Thus, particles without roughening and smaller size can act as promising catalysts.
\end{abstract}

\section{Introduction}

Although there are a large number of $\mathrm{ABO}_{3}$ simple perovskite, when one or more cations of the structure are replaced by other ones generates a group of compounds known as double perovskite, $\mathrm{AA}^{\prime} \mathrm{BB}^{\prime} \mathrm{O}_{3}$ or $\mathrm{A}_{2} \mathrm{BB}^{\prime} \mathrm{O}_{6}$. In these compounds, the difference of ionic radius or charge between $\mathrm{B}$ and $\mathrm{B}$ 'is large enough to form an ordered superstructure, with lattice parameter greater than a simple perovskite. The complex double perovskites can be classified as ordered and disordered type, depending on the degree of long-range order of $\mathrm{B}$ and $\mathrm{B}^{\prime}$ cations [1]. The double perovskite structure can be represented as a three-dimensional network of $\mathrm{B}$ and $\mathrm{B}^{\prime} \mathrm{O}_{6}$ octahedra, which alternate in structure with A cations occupying interstitial sites. In general, the A sites are preferably occupied by alkaline earth metal and A' by alkali metal. The B and B' sites are preferably occupied by transition metals [1]. Compounds with double perovskite structure are versatile, capable of generating a large family of solids. These compounds are investigated due to their physical properties as semiconducting, ferroelectric, dielectric, pyroelectric, piezoelectric and multiferroic $[2,3]$. Further, $\mathrm{A}_{2} \mathrm{BB}^{\prime} \mathrm{O}_{6}$ double perovskite type shows magnetic and magnetoresistance properties, while the $\mathrm{AA}^{\prime} \mathrm{BB}^{\prime} \mathrm{O}_{6}$ type have been investigated for their catalytic properties [4]. The catalytic activity of these oxides can be influenced by the A cation of the structure which provides thermal and structural resistance to the catalyst, while the $\mathrm{B}$ cation is responsible for the catalytic activity. However, the partial substitution of the A cation can strongly affect the catalytic activity of $\mathrm{B}$ cation, due to the stabilization of oxidation states and simultaneous formation of defects. In addition, the partial replacement of the B cation can modify the catalytic activity, whereas interfere directly in the electronic state, in the energy stabilization of the crystal field and in the binding energy. The partial replacement becomes, therefore, a fundamental tool for obtaining active, selective and stable materials for several applications. Thus, the knowing the structure of the catalyst is of fundamental importance for understanding the behavior of the species involved in a 
catalytic process, such as in biodiesel synthesis [5]. In this work, $\mathrm{Sr}_{0.8} \mathrm{~K}_{0.2} \mathrm{TiCu}_{0.10} \mathrm{O}_{3}$, $\mathrm{Sr}_{0.7} \mathrm{~K}_{0.3} \mathrm{TiCu}_{0.15} \mathrm{O}_{3}$ and $\mathrm{Sr}_{0.5} \mathrm{~K}_{0.5} \mathrm{TiCu}_{0.25} \mathrm{O}_{3}$ nanostructured particulate of double perovskite structure were prepared by spray pyrolysis method. This method allows to obtain material with high chemical and structural homogeneity, containing grains with controlled morphology and size, and high purity $[6,7]$. The characterization of compounds was carried out by X-ray diffraction, scanning electron microscopy and infrared spectroscopy.

\section{Experimental}

\section{Synthesis}

The synthesis of $\mathrm{Sr}_{0.8} \mathrm{~K}_{0.2} \mathrm{TiCu}_{0.10} \mathrm{O}_{3}, \mathrm{Sr}_{0.7} \mathrm{~K}_{0.3} \mathrm{TiCu}_{0.15} \mathrm{O}_{3}$ and $\mathrm{Sr}_{0.5} \mathrm{~K}_{0.5} \mathrm{TiCu}_{0.25} \mathrm{O}_{3}$ nanoparticles was performed by the spray pyrolysis method [6,7]. This method is based on the pyrolysis of an aerosol spray produced by ultrasound. This procedure allows the preparation of nanostructured powders, homogeneous in composition and in particle size, using the pyrolysis of an aerosol produced by ultrasonic spraying of a precursor solution, ensuring an excellent reproducibility [8-10]. This method can be considered as intermediate between synthetic techniques from a liquid phase and those in the vapor phase. The starting materials used were $\mathrm{TiCl}_{3}, \mathrm{KNO}_{3}, \mathrm{Cu}\left(\mathrm{NO}_{3}\right)_{2}$ and $\mathrm{Sr}\left(\mathrm{NO}_{3}\right)_{2}$. Then, a solution was prepared from a stoichiometric mixture of the starting reagents in deionized water. The solution was then placed in the spray container and was atomized by a high frequency ultrasonic generator. The aerosol generated was drawn into a tubular furnace using a carrier gas constituted of $\mathrm{N}_{2}$ and $\mathrm{O}_{2}$. Initially, carried out the synthesis of the $\mathrm{Sr}_{0.8} \mathrm{~K}_{0.2} \mathrm{TiCu}_{0.10} \mathrm{O}_{3}$ system, varying the air flow and the furnace temperature maintaining the fixed frequency ultrasound vibration. After optimized the best conditions of synthesis the $\mathrm{Sr}_{0.7} \mathrm{~K}_{0.3} \mathrm{TiCu}_{0.15} \mathrm{O}_{3}$ and $\mathrm{Sr}_{0.5} \mathrm{~K}_{0.5} \mathrm{TiCu}_{0.25} \mathrm{O}_{3}$ solid solutions were synthesized. Table 1 lists the experiments performed and the different conditions used. The best conditions for obtaining nanopowders homogeneous in composition and in particle size were in the concentration of $0.05 \mathrm{~mol} / \mathrm{L}$ solution with flow rate of $6 \mathrm{~L} / \mathrm{min}$ and at $700{ }^{\circ} \mathrm{C}$.

Table 1. Experimental conditions performed by $\mathrm{Sr}_{1-\mathrm{x}} \mathrm{K}_{\mathrm{x}} \mathrm{TiCu}_{\mathrm{x} / 2} \mathrm{O}_{3}$ systems, where $\mathrm{x}=0.2 ; 0.3$ and 0.5 .

\begin{tabular}{|c|c|c|c|c|}
\hline Experiments & $\mathbf{x}$ & $\begin{array}{c}\text { Concentration } \\
(\mathbf{m o l} / \mathbf{L})\end{array}$ & $\begin{array}{c}\text { Flux } \\
(\mathbf{L} / \mathbf{m i n})\end{array}$ & Temperature $\left(\mathbf{(}^{\mathbf{0}} \mathbf{C}\right)$ \\
\hline 1 & 0.2 & 0.05 & 6 & 900 \\
\hline 2 & 0.2 & 0.05 & 3 & 900 \\
\hline 3 & 0.2 & 0.05 & 6 & 700 \\
\hline 4 & 0.2 & 0.025 & 6 & 900 \\
\hline 5 & 0.5 & 0.05 & 6 & 700 \\
\hline 6 & 0.3 & 0.05 & 6 & 700 \\
\hline
\end{tabular}

Structural Characterization

Structural characterization of the $\mathrm{Sr}_{1-\mathrm{x}} \mathrm{K}_{\mathrm{x}} \mathrm{TiCu}_{\mathrm{x} / 2} \mathrm{O}_{3}$ solid solutions, where $\mathrm{x}=0.2,0.3$ and 0.5, was carried out by X-ray diffraction (XRD). A Siemens (model D-5000) diffractometer with $\mathrm{Cu}-\mathrm{K} \alpha$ radiation $(\lambda=1.54 \AA)$ and a graphite monochromator were used. Measurements were carried out over an angular range of $5^{\circ} \leq 2 \theta \leq 80^{\circ}$ with a scanning step of $0.02^{\circ}$ and a fixed counting time of $2.40 \mathrm{~s}$. [11]:

The crystallite size was estimated by Scherrer's equation using the Jade 8 Plus software

$$
D_{h k l}=\frac{K \lambda}{\beta \cos (\theta)}
$$

where $\mathrm{D}$ is the average crystallite size, $\beta$ is the broadening of the diffraction line measured at half of the maximum intensity, $\lambda$ is the wavelength $(\mathrm{Cu}-\mathrm{K \alpha}), \theta$ is the Bragg angle for a given diffraction, 
and $\mathrm{k}$ is a constant, which is in general equal to 0.9 for powders. Table 2 shows the average crystallite size of powders.

Table 2. Average crystallite size derived from Scherrer's equation for the de $\mathrm{Sr}_{1-\mathrm{x}} \mathrm{K}_{\mathrm{x}} \mathrm{TiCu}_{\mathrm{x} / 2} \mathrm{O}_{3}$ solid solutions, where $\mathrm{x}=0.2 ; 0.3$ and 0.5 .

\begin{tabular}{|c|c|c|c|}
\hline Compound & $\mathrm{Sr}_{0.8} \mathrm{~K}_{0.2} \mathrm{TiCu}_{0.10} \mathrm{O}_{3}$ & $\mathrm{Sr}_{0.7} \mathrm{~K}_{0.3} \mathrm{TiCu}_{0.15} \mathrm{O}_{3}$ & $\mathrm{Sr}_{0.5} \mathrm{~K}_{0.5} \mathrm{TiCu}_{0.25} \mathrm{O}_{3}$ \\
\hline $\mathrm{D}(\mathrm{nm})$ & 9.41 & 8.92 & 8.30 \\
\hline
\end{tabular}

The average crystallite size values shown in Table 2 were obtained for the solid solutions prepared by spray pyrolysis with concentration of $0.05 \mathrm{~mol} / \mathrm{L}$, flow rate of $6 \mathrm{~L} / \mathrm{min}$ and at temperature of $700{ }^{\circ} \mathrm{C}$. The synthesis performed with less air flow $(3 \mathrm{~L} / \mathrm{min})$ and higher temperature $\left(900{ }^{\circ} \mathrm{C}\right)$ showed a greater number of particles agglomerated and an increase in crystallite size to $14 \mathrm{~nm}$.

The powder morphology was analyzed by scanning electron microscopy (SEM) using a microscope model Carls Zeiss EVO LS15, operating at $30 \mathrm{kV}$. The samples were coated with a thin gold film.

\section{Results and Discussion}

\section{Structural Characterization by X-ray Diffraction}

Figure 1 shows the XRD patterns of $\mathrm{Sr}_{0.8} \mathrm{~K}_{0.2} \mathrm{TiCu}_{0.10} \mathrm{O}_{3}, \mathrm{Sr}_{0.7} \mathrm{~K}_{0.3} \mathrm{TiCu}_{0.15} \mathrm{O}_{3}$ and $\mathrm{Sr}_{0.5} \mathrm{~K}_{0.5} \mathrm{TiCu}_{0.25} \mathrm{O}_{3}$ powders obtained by the spray pyrolysis method, with solution concentration equal to $0.05 \mathrm{~mol} / \mathrm{L}$, air flow of $6 \mathrm{~L} / \mathrm{min}$ and temperature of $700{ }^{\circ} \mathrm{C}$ (Table 1). All XRD diffraction patterns exhibited only a set of diffraction lines ascribed to $\mathrm{SrTiO}_{3}$ single phase powders, which were identified from the JCPDS card number 35-0734 with cubic symmetry and space group Pm $3 \mathrm{~m}$ (221). The powder morphology was analyzed by scanning electron microscopy (SEM). Figure 2 shows the morphology of the powders obtained in experiments $1,2,3$, and 4 (Table 1). In experiment 1 some particles not present spherical shape. Larger particles are hollow, while the lower particles show aspect dense. The particles formed with lower gas flow, shown in experiment 2 , and with a longer time of passage in the furnace presented less crystalline than those of other experiments.

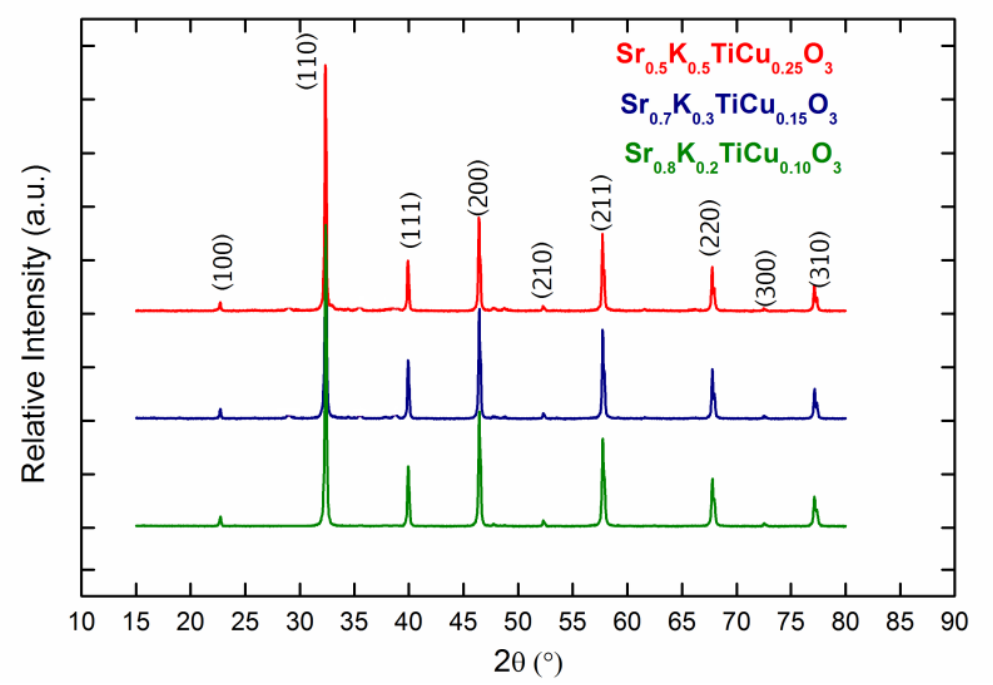

Fig. 1. $\mathrm{XRD}$ patterns of $\mathrm{Sr}_{0.8} \mathrm{~K}_{0.2} \mathrm{TiCu}_{0.10} \mathrm{O}_{3}, \mathrm{Sr}_{0.7} \mathrm{~K}_{0.3} \mathrm{TiCu}_{0.15} \mathrm{O}_{3}$ and $\mathrm{Sr}_{0.5} \mathrm{~K}_{0.5} \mathrm{TiCu}_{0.25} \mathrm{O}_{3}$ powders.

In experiment 3 , the surface of the particles showed a distinct aspect in relation to the particles obtained in experiments 1 and 2, since the visible crystallites in the surface are smaller. The larger particles showed small cavities. The particles of the experiment 4 showed more dense in the surface. An image with backscattered electrons is shown in Figure 3. In this image is observed the presence of a second phase not detected in X-ray diffraction. However, it was observed that the amorphous phase is less than $5 \%$ in volume, below the detection of $\mathrm{X}$-ray diffraction. 

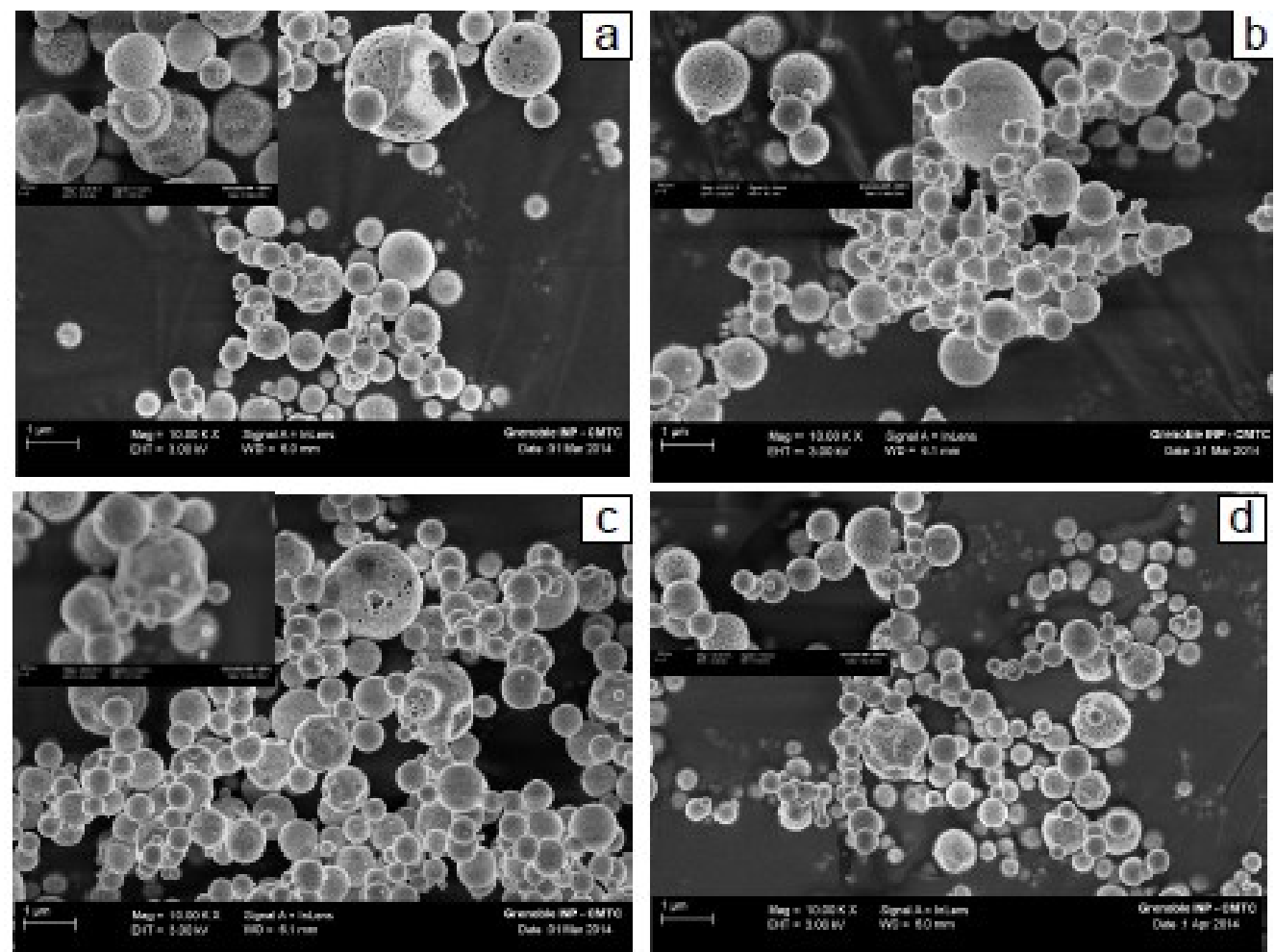

Fig. 2. (a) Experiment 1: $\mathrm{C}=0.05 \mathrm{~mol} / \mathrm{L} ; \mathrm{F}=6 \mathrm{~L} / \mathrm{min} ; \mathrm{T}=900{ }^{\circ} \mathrm{C}$; (b) Experiment 2 : $\mathrm{C}=0.05 \mathrm{~mol} / \mathrm{L} ; \mathrm{F}=3 \mathrm{~L} / \mathrm{min} ; \mathrm{T}=900{ }^{\circ} \mathrm{C}$; (c) Experiment $3: \mathrm{C}=0.05 \mathrm{~mol} / \mathrm{L} ; \mathrm{F}=6 \mathrm{~L} / \mathrm{min}$; $\mathrm{T}=700{ }^{\circ} \mathrm{C} ;(\mathrm{d})$ Experiment $4: \mathrm{C}=0.025 \mathrm{~mol} / \mathrm{L} ; \mathrm{F}=6 \mathrm{~L} / \mathrm{min} ; \mathrm{T}=900{ }^{\circ} \mathrm{C}$.
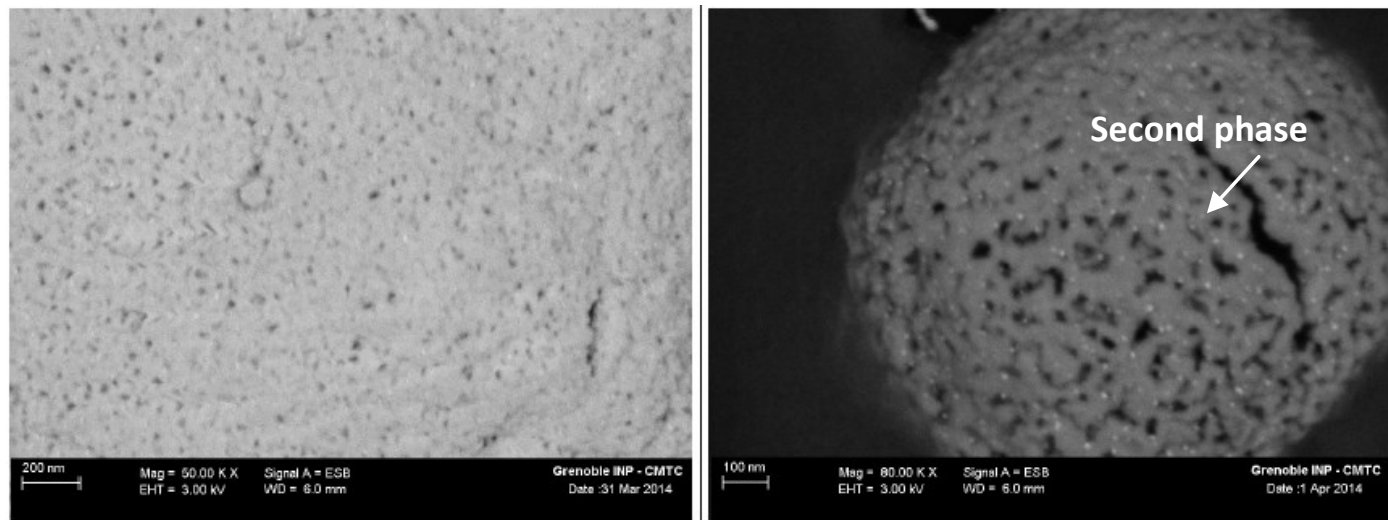

Fig. 3. Scanning electron microscopy images with $80.00 \mathrm{k}$ of increase. The second phase is represented by white points.

After investigating the powder morphology related with the $\mathrm{Sr}_{1-\mathrm{x}} \mathrm{K}_{\mathrm{x}} \mathrm{TiCu}_{\mathrm{x} / 2} \mathrm{O}_{3}$ system, for $\mathrm{x}=0.2$, was analyzed the particle morphology of the experiments 5 and 6 (Table 1), where $\mathrm{x}=0.3$ to 0.5 , respectively. The Increase of the $x$ value showed a modification in the surface of the particles, a large part of them presented with spherical shape, smooth and with small agglomerates. This phenomenon suggests that the stoichiometry changes the aspect of the particle surface, which can influence in the catalytic activity. Thus, the particles without roughening and smaller size can act as promising catalysts. Figure 4 shows the morphology of powders obtained in the experiments 5 and 6 characterized by scanning electron microscopy (SEM). 


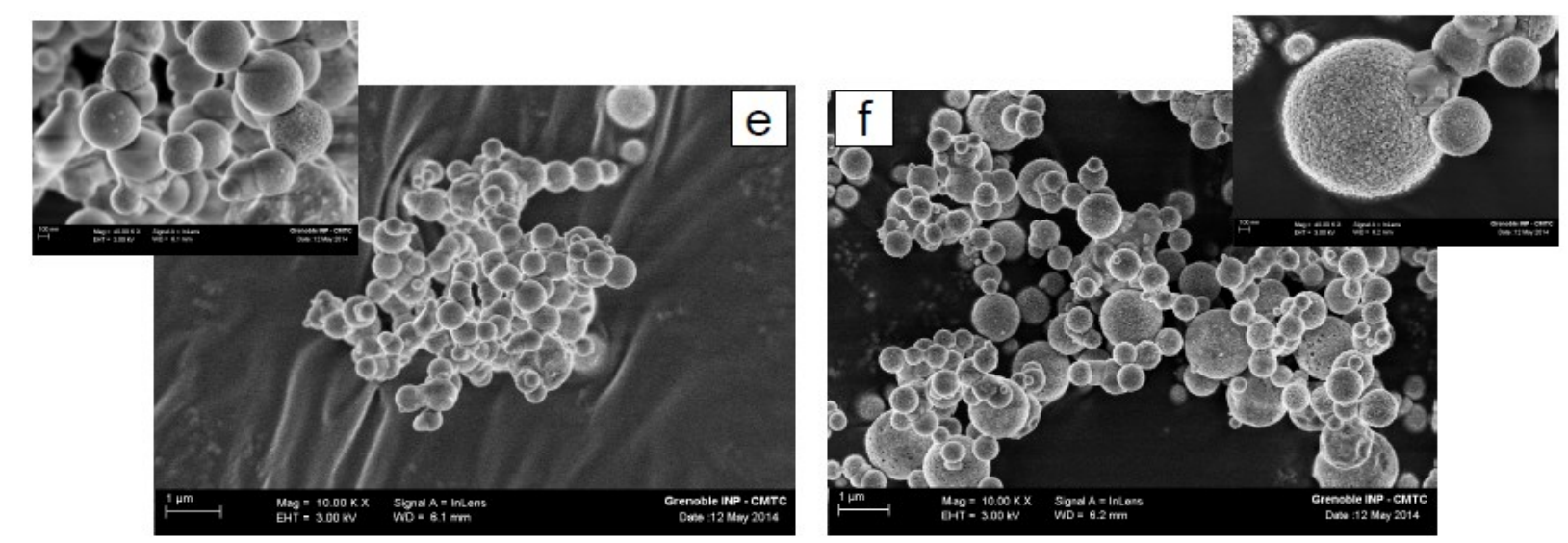

Fig. 4. Scanning electron microscopy images of $\mathrm{Sr}_{1-\mathrm{x}} \mathrm{K}_{\mathrm{x}} \mathrm{TiCu}_{\mathrm{x} / 2} \mathrm{O}_{3}$ powder: (e) $\mathrm{x}=0.3$; (f) $\mathrm{x}=0.5$.

Tests carried out under different conditions to obtain powders by spray pyrolysis showed that the air flow influences in the particle shape. Reducing the air flow showed a tendency to obtain agglomerated particles. The SEM image showed that particles size ranging from 200 to $400 \mathrm{~nm}$ were formed, while the DRX showed average crystallite size at around $9 \mathrm{~nm}$ (Table 2). The difference between the crystallite size calculated using X-ray diffraction data and the particle size obtained by SEM is due to the fact that the particles are composed of several crystalline domains, which were observed by X-ray diffraction, while the whole particle was observed in SEM.

\section{Conclusions}

From the spray pyrolysis method was possible to obtain single and nanometric powders of strontium titanate with the space group $\mathrm{Pm} \overline{3} \mathrm{~m}$ (221) and cubic symmetry. The tests performed at different concentrations, air flow and temperature have shown that the air flow influences in the shape of the particles, obtaining agglomerated particles with its reduction. Further, at higher temperature, there was an increase in the average crystallite size. The morphological analysis of the powders showed that the $\mathrm{Sr}_{0.5} \mathrm{~K}_{0.5} \mathrm{TiCu}_{0.25} \mathrm{O}_{3}$ system presented particles with smooth and spherical surfaces and with small agglomerates without roughness and lower average crystallite size, showing to be a promising catalyst.

\section{Acknowledgments}

The authors are grateful to the Brazilian research agencies: FAPESP, CNPq and UNESP/PROPe for financial support.

\section{References}

[1] R. Shaheen, J. Bashir, H. Rundlöf, A.R. Rennie:Mater. Lett. Vol. 59 (2005), p. 2296.

[2] Y. Shimakawa, M. Azuma, N. Ichikawa: Materials Vol. 4 (2011), p. 153.

[3] R. Koduri, M. Lopez: J. Mater. Sci.-Mater. In Electron. Vol. 19 (2008), p. 669.

[4] R.S. Hu, R.R. Ding, J. Chen, J. Hu, Y. Zhang: Catal. Commun Vol. 21 (2012), p. 38.

[5] F.E. Lopez Suarez, A. Bueno Lopez, M.J. Illan Gomez, B. Ura, J. Trawczynski: Catal. Today Vol. 176 (2011), p. 182.

[6] E. Djurado, E. Meunier: J. Solid. State Chem. Vol. 141 (1998), p. 191.

[7] P.Vernoux, E. Djurado, M. Guillodo: J. Am. Ceram. Soc. Vol. 84 (2001), p. 2289.

[8] P.A. Stuart, T. Unno, R. Ayres-Rocha, E. Djurado, S. J. Skinner: J. Eur. Ceram. Soc.Vol. 29 (2009), p. 697.

[9] D. Mesguich, J. M. Bassat, C. Aymonier, A. Brüll, L. Dessemond, E. Djurado: Electrochim. Acta Vol 87 (2013), p. 330.

[10] C. Goulart, E. Djurado: J. Eur. Ceram. Soc. Vol. 33 (2013), p. 769.

[11] Jade 8 Plus, Xrd Pattern Processing and Identification Program, Materials Data, Inc. 19952007. 
Reproduced with permission of copyright owner. Further reproduction prohibited without permission. 